\title{
A Handheld Metabolic Device (Lumen) to Measure Fuel Utilization in Healthy Young Adults: Device Validation Study
}

Kent Arnold Lorenz ${ }^{1}$, PhD; Shlomo Yeshurun ${ }^{2}$, PhD; Richard Aziz ${ }^{1}$, MSc; Julissa Ortiz-Delatorre ${ }^{1}$, BSc; James Robert Bagley $^{1}$, PhD; Merav Mor ${ }^{2}$, PhD; Marialice Kern ${ }^{1}$, PhD

${ }^{1}$ Department of Kinesiology, San Francisco State University, San Francisco, CA, United States

${ }^{2}$ Metaflow Ltd, Tel Aviv, Israel

Corresponding Author:

Kent Arnold Lorenz, PhD

Department of Kinesiology

San Francisco State University

1600 Holloway Ave

GYM 101

San Francisco, CA, 94132

United States

Phone: 14153382244

Email: kalorenz@sfsu.edu

\section{Abstract}

Background: Metabolic carts measure the carbon dioxide $\left(\mathrm{CO}_{2}\right)$ produced and oxygen consumed by an individual when breathing to assess metabolic fuel usage (carbohydrates versus fats). However, these systems are expensive, time-consuming, and only available in health care laboratory settings. A small handheld device capable of determining metabolic fuel usage via $\mathrm{CO}_{2}$ from exhaled air has been developed.

Objective: The aim of this study is to evaluate the validity of a novel handheld device (Lumen) for measuring metabolic fuel utilization in healthy young adults.

Methods: Metabolic fuel usage was assessed in healthy participants ( $\mathrm{n}=33$; mean age 23.1 years, SD 3.9 years) via respiratory exchange ratio (RER) values obtained from a metabolic cart as well as $\% \mathrm{CO}_{2}$ from the Lumen device. Measurements were performed at rest in two conditions: fasting, and after consuming 150 grams of glucose, in order to determine changes in metabolic fuel usage. Reduced major axis regression and simple linear regression were performed to test for agreement between RER and Lumen $\% \mathrm{CO}_{2}$.

Results: Both RER and Lumen $\% \mathrm{CO}_{2}$ significantly increased after glucose intake $(P<.001$ for both) compared with fasting conditions, by 0.089 and 0.28 , respectively. Regression analyses revealed an agreement between the two measurements $\left(F_{1,63}=18.54\right.$; $P<.001)$.

Conclusions: This study shows the validity of Lumen for detecting changes in metabolic fuel utilization in a comparable manner with a laboratory standard metabolic cart, providing the ability for real-time metabolic information for users under any circumstances.

(Interact J Med Res 2021;10(2):e25371) doi: 10.2196/25371

\section{KEYWORDS}

resting metabolic rate; Lumen; ParvoMedics TrueOne 2400; validation; respiratory exchange ratio; metabolism; fuel utilization; indirect calorimetry; breath; lung; respiratory; young adult; measurement; testing

\section{Introduction}

Indirect calorimetry (metabolic cart), which is currently the preferred method for determining metabolic fuel utilization, measures the carbon dioxide produced $\left(\mathrm{VCO}_{2}\right)$ and oxygen consumed $\left(\mathrm{VO}_{2}\right)$ when breathing. The ratio between $\mathrm{VCO}_{2}$ and $\mathrm{VO}_{2}$ is the respiratory exchange ratio (RER), which provides insight into the relative contribution of carbohydrates and lipids to overall energy expenditure $[1,2]$. Though indirect calorimetry is not invasive, this method is time-consuming (up to 40 
minutes), only available in test laboratory settings, and requires technical and physiological expertise for handling the metabolic cart and interpretation of the metabolic data obtained.

Metaflow Ltd developed Lumen, a novel metabolic fuel utilization breathalyzer, which is a personalized handheld device that provides an individual's metabolic state in real time by measuring $\mathrm{CO}_{2}$ from exhaled breath (Figure 1). The device indirectly measures metabolic fuel usage via a $\mathrm{CO}_{2}$ sensor and a flow sensor to determine the rate of $\mathrm{CO}_{2}$ production from a single breath maneuver. The $\% \mathrm{CO}_{2}$ in the exhaled volume of air is determined from a specific breathing maneuver with a breath hold of 10 seconds. This concept is based on the fact that oxygen consumption is stable under resting conditions [3]; thus, a change in metabolic fuel use will generally be represented by changes in $\mathrm{CO}_{2}$ production. For carbohydrate oxidation, more carbon dioxide is produced relative to the consumption of oxygen. For fat oxidation, less carbon dioxide is produced [4]. The use of a smartphone app enables the user to track metabolic status outside of physiologic test laboratories.

Figure 1. A schematic representation of the Lumen device and app.
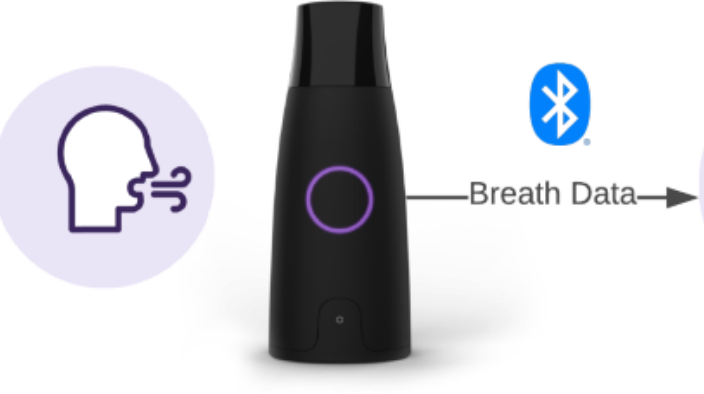

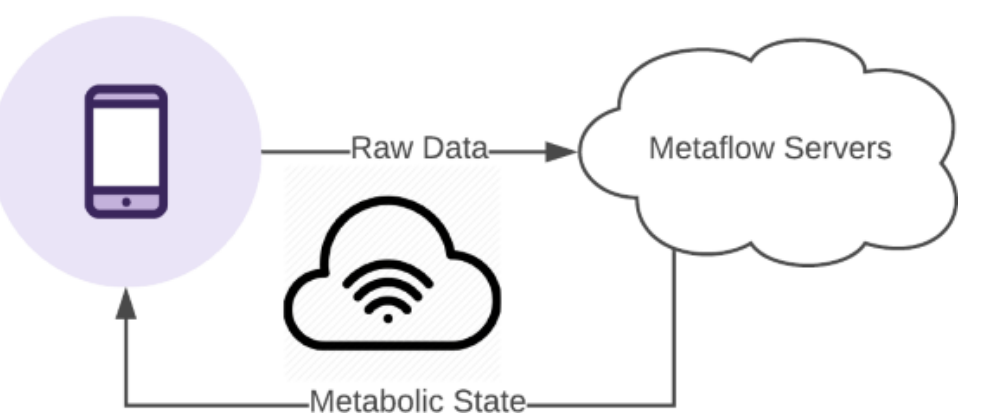

measurement day. All participants came to the test laboratory between $7 \mathrm{AM}$ and $11 \mathrm{AM}$ after a 12-hour fast and had abstained from any form of physical activity (other than walking).

On the laboratory testing day, blood glucose samples were taken by sterile finger prick blood sample and measured by a glucometer (OneTouch, LifeScan Inc). For the indirect calorimetry measurement, the participant had to lay down in supine position on a padded examination table, where a rigid clear plastic canopy with a comfortable, flexible seal was placed over the head and upper part of the torso. Once the metabolic cart measurement was completed, the participant was seated in a comfortable chair. After 5 minutes of rest, they were asked to perform two Lumen breath sessions (5-minute break between each session). The first Lumen session immediately after the metabolic cart measurement was used for data analysis. In case of an invalid first session (difference between breaths $>0.2 \%$ $\mathrm{CO}_{2}$ ), the second session was used for analysis.

Once finished, participants were asked to drink 150 grams of a glucose solution (3 servings of 50 grams with 20-minute intervals between each serving). Subsequently, 45 minutes after the intake of the first drink (corresponding to 5 minutes after finishing the last serving), their glucose levels were reassessed, and the same assessment procedures as during the fasted state before the glucose intake were repeated. Participants were removed from the analysis if they were unable to finish all glucose drinks.

\section{Metabolic Cart}

RER was analyzed using a calibrated TrueOne 2400 metabolic cart (ParvoMedics), which was previously determined to provide a valid measurement for RER with 5\% coefficient of variation [5]. This system uses a paramagnetic oxygen analyzer and infrared carbon dioxide analyzer with a Hans Rudolph heated pneumotach. The ParvoMedics system was warmed up for at least 60 minutes each day before testing to ensure accurate and minimum amount of home breath sessions were collected, participants were scheduled for the study laboratory 
stable readings. The gas analyzers and flow sensor were calibrated as per manufacturer's recommendations: calibration of the analyzers was performed using a high-precision gas mixture $\left(\mathrm{O}_{2}, \mathrm{CO}_{2}\right.$, remainder $\left.\mathrm{N}_{2}\right)$ and calibrated and accepted with a $<0.1 \%$ error with the calibration gas. Flow and volume were calibrated using a calibrated $3 \mathrm{~L}$ syringe (Hans Rudolph, model 5530) to $\leq 1 \%$ error. In addition, verification of the calibration process was performed to ensure stability of the system. The ambient temperature was kept between $22{ }^{\circ} \mathrm{C}$ and $26^{\circ} \mathrm{C}$ in the test laboratory. Relative humidity was maintained stable at roughly $60 \%$. Once calibration was acceptable and complete, a ventilated hood with subject cover was placed over the participant's head and positioned around the upper torso area to ensure no air could escape from the hood. The participants were required to stay awake during the measurement procedure. The hood ventilation was measured during the recording, and $\mathrm{CO}_{2}$ and $\mathrm{O}_{2}$ concentrations were measured from it. $\mathrm{VCO}_{2}$ and $\mathrm{VO}_{2}$ parameters were calculated and taken as 30 -second averages. For this study, we defined the subject steady-state metabolic measurement based on observed variations in the $\mathrm{VO}_{2}$ and $\mathrm{VCO}_{2}$ of less than $\leq 5 \%$ coefficient of variation for a period of at least five consecutive minutes, with a subsequent RER stability of $2.5 \%$ in a fasted state and $3.7 \%$ after glucose consumption, in a similar manner to previous studies [6]. Inability to meet these criteria resulted in removal of the data from the analysis.

\section{Lumen}

Lumen is a device designed to be calibration-free, with a warm-up time of less than 10 seconds and the $\mathrm{CO}_{2}$ sensor taking into account the room $\mathrm{CO}_{2}$ concentration during every measurement. During the measurement day, participants completed 2 sessions of 3 Lumen breaths each after the metabolic cart measurement. The Lumen breathing maneuver consists of three phases, starting from the end of a normal expiration (functional residual capacity). The participant takes a deep breath in through the Lumen device, followed by a 10 -second breath hold. Afterward, the subject exhales through the Lumen device, with a steady exhalation flow to at least the starting level of the maneuver. In order to confirm repeatability, breaths are taken in triplicate for each session. The Lumen smartphone app guides the participant through each phase of the Lumen maneuver. Each Lumen session was repeated after a 5-minute pause interval. Validity of breath maneuvers was systematically evaluated by the Lumen app. Inability to perform valid Lumen breath measures resulted in removal of the data from the analysis.

\section{Statistical Analyses}

All variables were tested and visualized for normal distribution before the tests.

To evaluate the changes after glucose intake, two-tailed paired parametric $t$ tests were performed for blood glucose levels, RER levels, and Lumen $\% \mathrm{CO}_{2}$ before and after glucose intake.

For agreement validation, major axis regression (Deming method) was performed to compare RER of the metabolic cart and $\% \mathrm{CO}_{2}$ from the Lumen device [7]. As RER and $\% \mathrm{CO}_{2}$ are in different units, the analysis is identical to ordinary least products regression (also known as reduced major axis regression), which is the most suitable analysis for comparison between two methods of measurement [8]. Moreover, a simple linear regression (ordinary least squares) was performed to determine the ability to predict Lumen values from the gold-standard value of RER.

Statistical analyses were performed using GraphPad Prism 8 (GraphPad Software Inc). The threshold for significance was set at $P<.05$.

\section{Ethics Statement}

This study was approved by San Francisco State University's Institutional Review Board for Human Subjects, and written informed consent was obtained from each participant before testing.

\section{Results}

From the original 54 participants recruited, 12 were excluded prior to laboratory testing and 9 had to be excluded during the testing day for failing to meet the inclusion criteria as detailed in the methods section: 1 participant was unable to consume all glucose drinks due to nausea, 3 participants did not achieve 5 minutes of stable metabolic cart measurement (coefficient of variation $<5 \%$ in $\mathrm{VO}_{2}$ and $\mathrm{VCO}_{2}$ ), and 5 participants were unable to perform a valid Lumen measurement (Figure 2). Characteristics of the final 33 participants are presented in Table 1 . 
Figure 2. Consolidated Standards of Reporting Trials (CONSORT) flow diagram. CV: coefficient of variation.

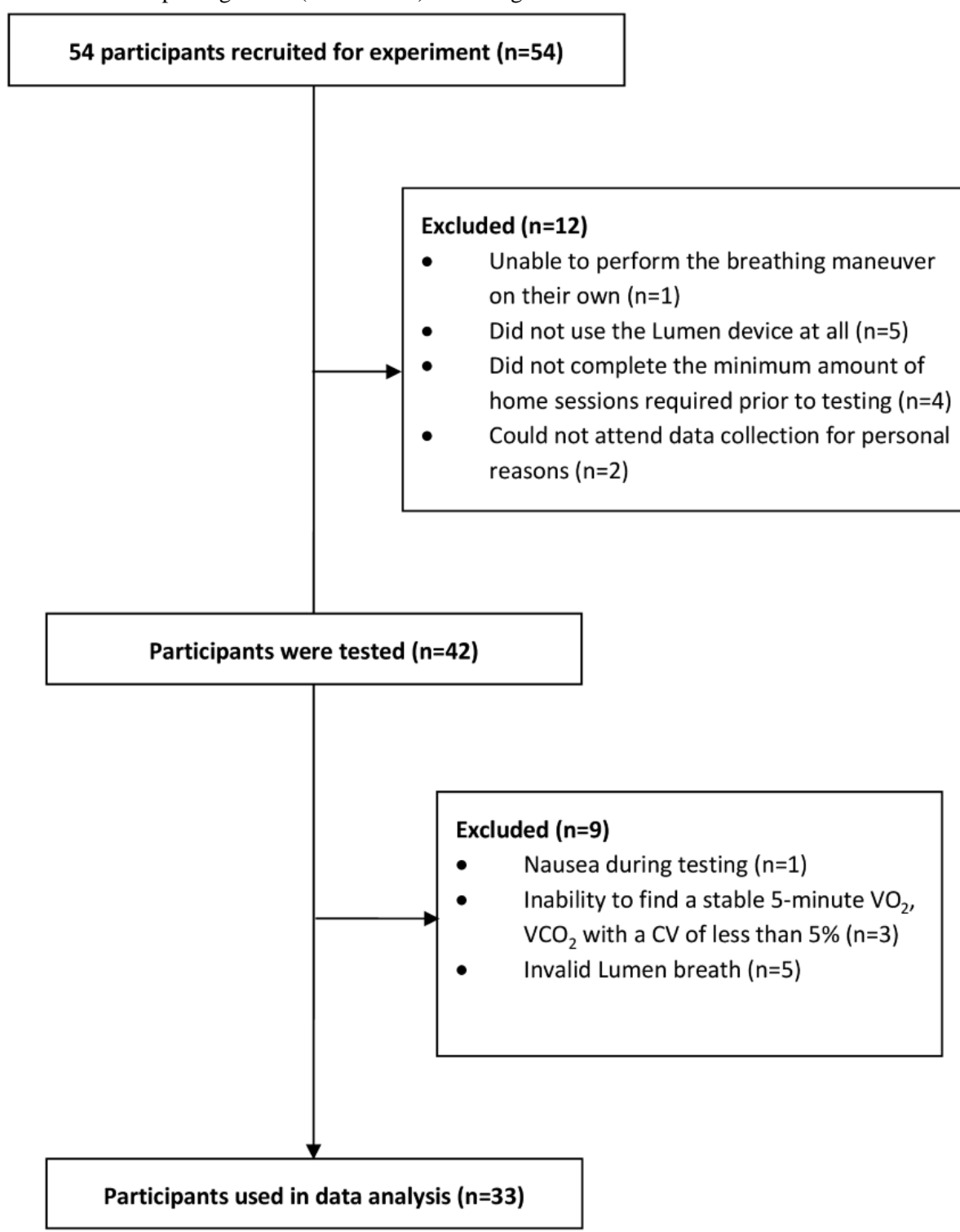

Table 1. Descriptive statistics of study participants.

\begin{tabular}{llllll}
\hline Gender & Count & Age (years), mean $(\mathrm{SD})$ & Weight $(\mathrm{kg})$, mean $(\mathrm{SD})$ & Height $(\mathrm{cm})$, mean $(\mathrm{SD})$ & BMI $\left(\mathrm{kg} / \mathrm{m}^{2}\right)$, mean $(\mathrm{SD})$ \\
\hline Male & 17 & $24.0(3.0)$ & $73.7(10.2)$ & $171.7(7.8)$ & $24.9(2.5)$ \\
Female & 16 & $22.3(4.5)$ & $59.1(6.4)$ & $160.9(5.5)$ & $22.9(2.6)$ \\
Total & 33 & $23.1(3.9)$ & $66.2(11.1)$ & $166.1(8.6)$ & $23.9(2.7)$ \\
\hline
\end{tabular}

Blood glucose levels increased from 90.6 (SD 9.2) $\mathrm{mg} / \mathrm{dL}$ to concentrations significantly rose from 4.20 (SD 0.4 ) to 4.48 145.2 (SD 25.3) $\mathrm{mg} / \mathrm{dL}$ as a result of glucose intake $\left(t_{32}=11.04, \quad\right.$ (SD 0.34; $t_{32}=5.978, P<.001$; Figure $\left.3 \mathrm{C}\right)$. These analyses have $P<.001$; Figure 3A). RER levels increased from 0.787 (SD confirmed the ability of both the metabolic cart and Lumen to 0.043 ) to 0.876 (SD 0.053) in response to glucose intake detect changes in metabolic fuel utilization.

$\left(t_{32}=10.84, P<.001\right.$; Figure $\left.3 \mathrm{~B}\right)$. Moreover, Lumen $\mathrm{CO}_{2}$ 
Figure 3. Changes in blood glucose as determined by (A) blood glucose test, (B) RER, and (C) Lumen $\% \mathrm{CO}_{2}$. Data are presented as mean (SD). N=33 for each state. $* * * *$ indicates $P<.001$. RER: respiratory exchange ratio.

A

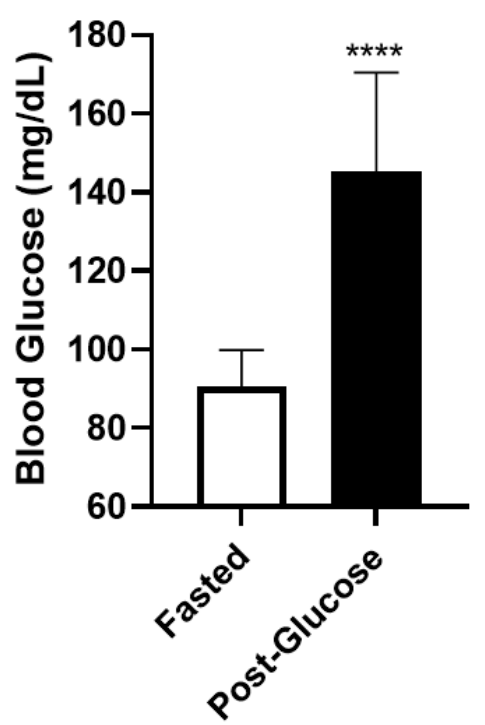

B

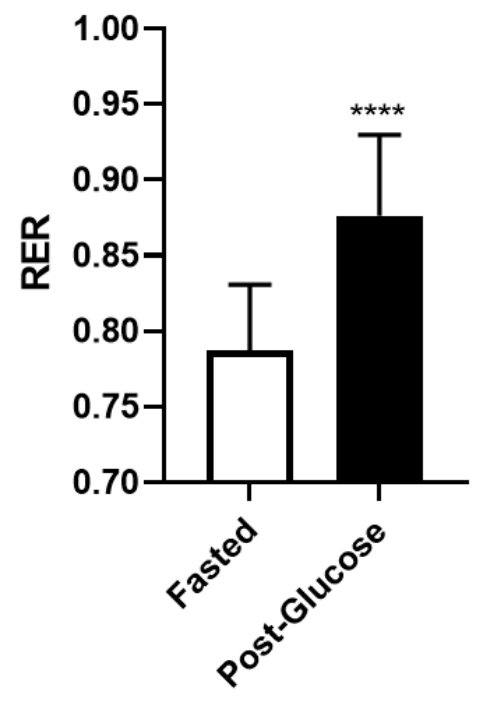

C

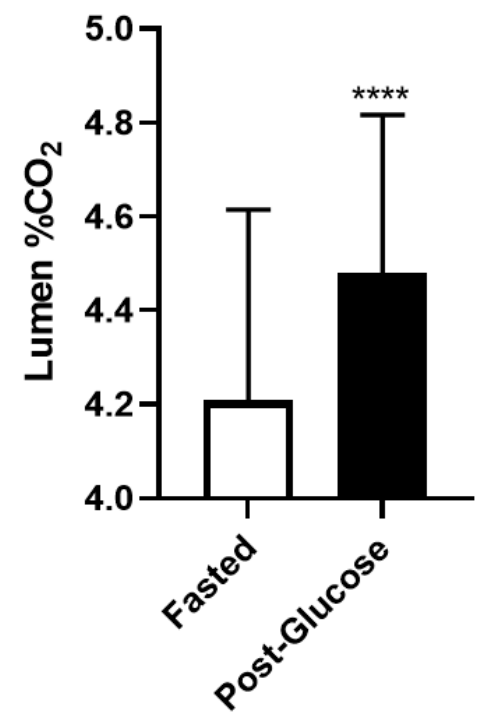

To test for agreement between RER units from the metabolic cart and $\% \mathrm{CO}_{2}$ from Lumen, reduced major axis regression was performed [9]. It revealed a significant relationship between $\mathrm{RER}$ and Lumen $\% \quad \mathrm{CO}_{2} \quad\left(F_{1,63}=18.54, \quad P<.001\right.$, $y=6.111 x-0.7445, x$-intercept $=0.1218$; Figure 4). This analysis confirmed the agreement between Lumen $\% \mathrm{CO}_{2}$ and metabolic cart RER, with a systemic bias as a result of the nature of the different units.

Figure 4. Reduced major axis regression of RER from the metabolic cart and Lumen $\% \mathrm{CO}_{2}$ measurements for metabolic activity. $\mathrm{N}=33$ for each state. RER: respiratory exchange ratio.

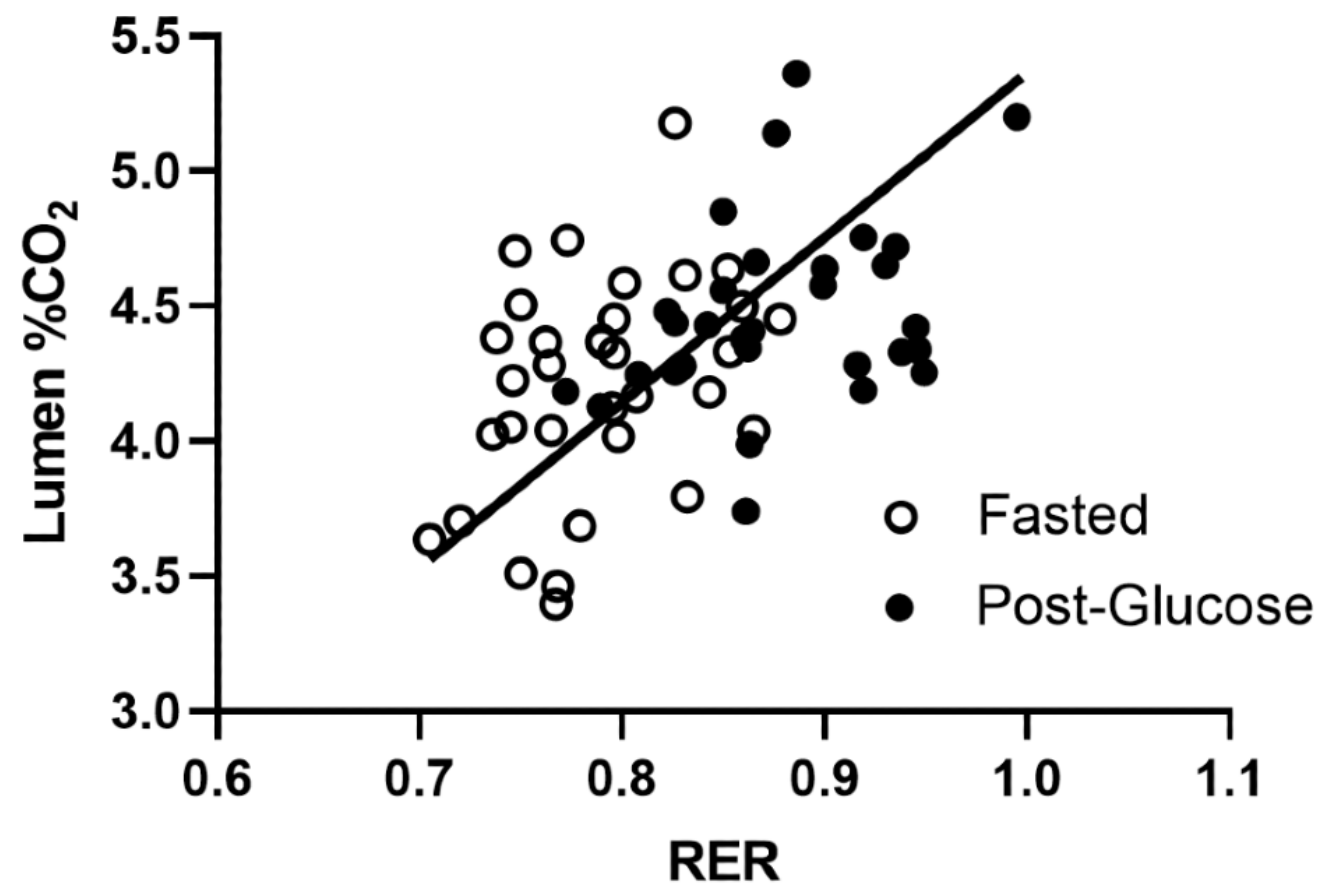

To determine the ability of metabolic cart RER to predict Lumen $\% \mathrm{CO}_{2}$, ordinary least squares regression was performed to estimate Lumen values from RER measures, with the assumption that RER is an accurate independent measure, to predict Lumen $\% \mathrm{CO}_{2}$. A significant model effect was present $\left(F_{1,63}=18.54\right.$, $P<.001, R^{2}=0.2274$; Figure 5). The RER parameter estimate indicated that for every 1-unit increase in RER, a 2.914-unit increase (SE 0.6767) in Lumen \% $\mathrm{CO}_{2}$ is expected. Since a full unit increase in RER is not a plausible outcome, this parameter estimate can be interpreted similarly by a 0.1 -unit increase in RER (eg, 0.7 to 0.8 ) to produce a 0.2914-unit increase in Lumen $\% \mathrm{CO}_{2}$. 
Figure 5. Ordinary least squares regression of RER and Lumen $\% \mathrm{CO}_{2} . \mathrm{N}=33$ for each state. RER: respiratory exchange ratio.

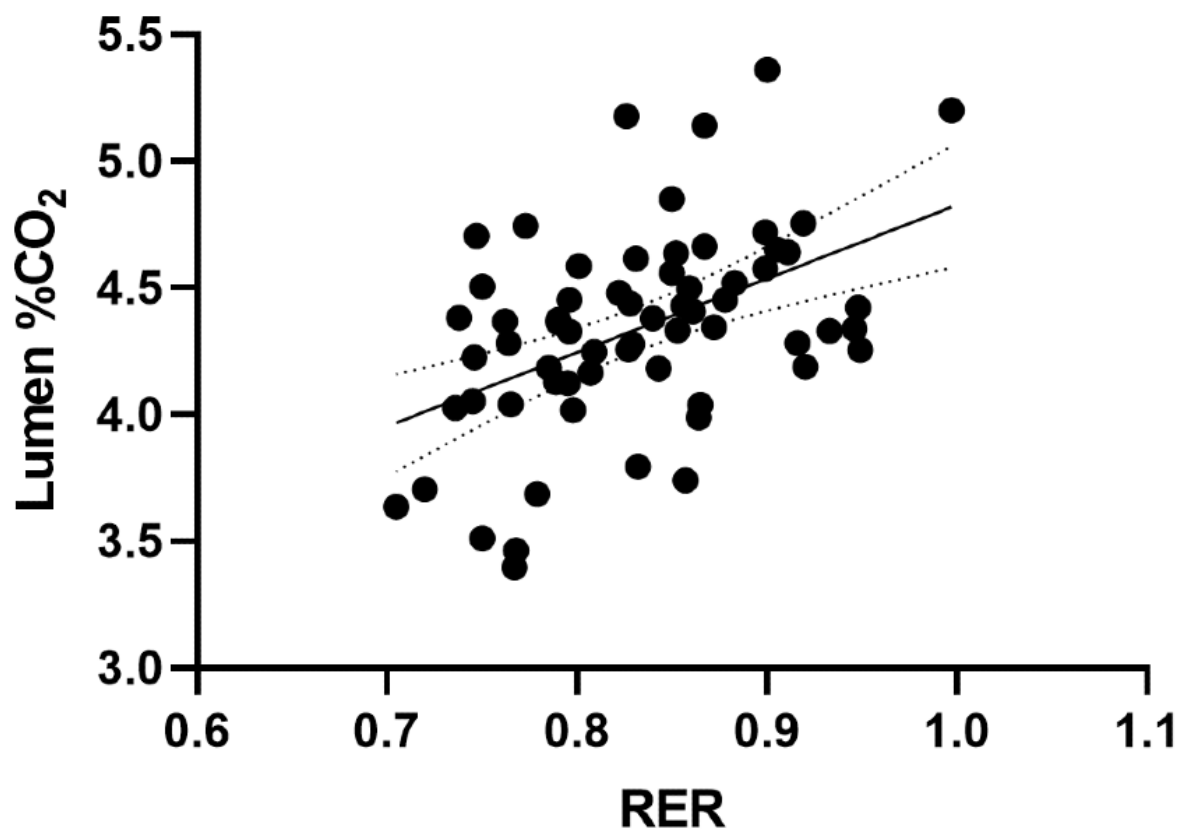

\section{Discussion}

\section{Principal Findings}

This study evaluated the ability of the Lumen device to assess changes in the body's metabolic fuel utilization in healthy young adults compared to the indirect calorimetry metabolic cart measurement. Our results show that Lumen $\mathrm{CO}_{2}$ levels are in agreement with RER values from the metabolic cart, which correspond to relative changes in metabolic fuel utilization.

Both Lumen $\mathrm{CO}_{2}$ levels and metabolic cart RER showed significant increases in metabolic levels as a result of glucose intake in healthy individuals in resting conditions (Figure 3). These results can be expected, as cells using more carbohydrates as fuel produce more $\mathrm{CO}_{2}$ relative to $\mathrm{O}_{2}$ consumption compared to cells metabolizing fat. The ratio between $\mathrm{CO}_{2}$ production and $\mathrm{O}_{2}$ consumption in this process is known as the respiratory quotient (RQ) or RER. RQ and RER vary depending on the energy source of the cell (carbohydrate versus fat), and the acronyms are commonly used interchangeably $[2,10,11]$. In resting conditions, oxygen consumption is fairly stable [12,13], meaning that participants' changes in RQ are due to changes in $\mathrm{CO}_{2}$ production. This is the underlying concept of the Lumen device, enabling it to track changes in metabolic fuel utilization. For that reason, it was important to ensure that participants in this study were at rest before and during their measurements.

Reduced major axis regression revealed an agreement between RER and Lumen $\mathrm{CO}_{2}$ levels (Figure 4). This analysis enables us to test for agreement between methods with different units and verify the validity of the Lumen device with a metabolic cart. It demonstrates the ability of the Lumen device to provide equivalent results to the metabolic cart in assessing metabolic fuel utilization.

Furthermore, the results from the simple linear regression predicting Lumen $\% \mathrm{CO}_{2}$ using RER values suggest that, while there is measurement agreement between the Lumen $\% \mathrm{CO}_{2}$ and RER, the proportion of variance remains low (Figure 5). Thus, Lumen can be seen to be an effective instrument for monitoring individual changes in metabolic responses (within-subject consistency), rather than a substitute for the metabolic cart (between-subject precision).

Evidence suggests that the assessment of RER can be beneficial for multiple applications, such as nutrition, diabetes prevention, or weight management [14]. It has previously been shown that RER could be a prognostic marker of weight loss and a predictor of weight gain $[15,16]$. Moreover, minute-to-minute RER measured in a respiratory chamber calorimeter showed that the slopes of RER were different in response to different dietary interventions [17]. However, although RER is currently the preferred method for determining metabolic fuel, it is a time-consuming, uncomfortable, and costly and impractical tool for real-time day-to-day assessments of metabolic activity. In contrast, the Lumen device is small, mobile, user-specific, and relatively cheap, and delivers the outcome immediately to the user and enables real-time decisions.

\section{Limitations}

This study is the first to show agreement between Lumen \% $\mathrm{CO}_{2}$ and RER. However, it is important to note that participants in this study were young (mean age 22.4 years) and healthy individuals. With increasing age, metabolism changes, as can be seen in various metabolic cart studies [18-20]. Future studies will need to examine whether RER metabolic cart levels correspond to Lumen $\mathrm{CO}_{2}$ levels in older subjects and those with metabolic conditions.

Unlike the metabolic cart, the Lumen device does not measure oxygen consumption. Accordingly, the Lumen measurement should be performed under resting conditions with stable $\mathrm{VO}_{2}$, allowing the correct interpretation of changes of $\% \mathrm{CO}_{2}$ as changes in metabolic state. 
In addition, results from this study showed a high peak of blood glucose levels 45 minutes after glucose intake ( 5 minutes after the third drink), whereas both RER and Lumen $\% \mathrm{CO}_{2}$ showed a more moderate increase in levels. It is possible that the metabolic cart and Lumen measurements were performed too early, as it may be that in some of our participants, the peak glucose levels occurred more than 45 minutes after ingestion; thus, it was not yet fully metabolized [21].

\section{Conclusions}

In summary, Lumen can provide valid information regarding an individual's metabolic state, and in agreement with results from the metabolic cart. Unlike the metabolic cart, Lumen measurement can be performed anywhere, anytime, without the need for a specialized laboratory, equipment, and technical staff. The Lumen device is able to detect changes in metabolism due to dietary intake, similarly to the metabolic cart. The capability of taking metabolic measurements continuously outside of laboratory settings can provide new insights about the metabolic state of an individual so as to obtain further knowledge and understanding about metabolism and nutrition.

\section{Acknowledgments}

This work was supported by Metaflow Ltd. We would like to thank the participants for their time in taking part in this study, and the Lumen team for their support. We would like to acknowledge Casey Curl for his work in setting up the protocols and procedures during preliminary testing.

\section{Authors' Contributions}

KAL and SY analyzed the data and prepared the manuscript. RA and JO coordinated the project and collected the data. JRB reviewed and edited the manuscript. MM and MK conceived, designed, and supervised the study as well as reviewed and edited the manuscript. All authors approved the manuscript before submission.

\section{Conflicts of Interest}

SY and MM are employees of Metaflow Ltd, and contributed to the design and analysis of the study as well as the preparation of the manuscript. The other authors declare no conflicts of interest.

\section{References}

1. Livesey G, Elia M. Estimation of energy expenditure, net carbohydrate utilization, and net fat oxidation and synthesis by indirect calorimetry: evaluation of errors with special reference to the detailed composition of fuels. Am J Clin Nutr 1988 Apr;47(4):608-628. [doi: 10.1093/ajcn/47.4.608] [Medline: 3281434]

2. McClave SA, Lowen CC, Kleber MJ, McConnell JW, Jung LY, Goldsmith LJ. Clinical use of the respiratory quotient obtained from indirect calorimetry. JPEN J Parenter Enteral Nutr 2003;27(1):21-26. [doi: 10.1177/014860710302700121] [Medline: 12549594]

3. Moon JK, Butte NF. Combined heart rate and activity improve estimates of oxygen consumption and carbon dioxide production rates. J Appl Physiol (1985) 1996 Oct 01;81(4):1754-1761 [FREE Full text] [doi: 10.1152/jappl.1996.81.4.1754] [Medline: 8904596]

4. Elia M, Livesey G. Theory and validity of indirect calorimetry during net lipid synthesis. Am J Clin Nutr 1988 Apr;47(4):591-607. [doi: 10.1093/ajcn/47.4.591] [Medline: $\underline{3281433}$ ]

5. Cooper JA, Watras AC, O'Brien MJ, Luke A, Dobratz JR, Earthman CP, et al. Assessing validity and reliability of resting metabolic rate in six gas analysis systems. J Am Diet Assoc 2009 Jan;109(1):128-132 [FREE Full text] [doi: 10.1016/j.jada.2008.10.004] [Medline: 19103333]

6. Corbin K, Krajmalnik-Brown R, Carnero E, Bock C, Emerson R, Rittmann B, et al. Integrative and quantitative bioenergetics: Design of a study to assess the impact of the gut microbiome on host energy balance. Contemp Clin Trials Commun 2020 Sep;19:100646 [FREE Full text] [doi: 10.1016/j.conctc.2020.100646] [Medline: 32875141]

7. Brace RA. Fitting straight lines to experimental data. American Journal of Physiology-Regulatory, Integrative and Comparative Physiology 1977 Sep 01;233(3):R94-R99. [doi: 10.1152/ajpregu.1977.233.3.r94]

8. Ludbrook J. Linear regression analysis for comparing two measurers or methods of measurement: but which regression? Clin Exp Pharmacol Physiol 2010 Jul;37(7):692-699. [doi: 10.1111/j.1440-1681.2010.05376.x] [Medline: 20337658]

9. Ludbrook J. Comparing methods of measurements. Clin Exp Pharmacol Physiol 1997 Feb;24(2):193-203. [doi: 10.1111/j.1440-1681.1997.tb01807.x] [Medline: 9075596]

10. Benedict F, Cathcart E. Muscular Work, a Metabolic Study with Special Reference to the Efficiency of the Human Body as a Machine. Washington, DC: Carnegie Institution of Washington; 1913.

11. Brooks GA, Fahey TD, Baldwin KM. Exercise Physiology: Human Bioenergetics and Its Applications. New York, NY: McGraw-Hill Education; 2004.

12. Spurr GB, Prentice AM, Murgatroyd PR, Goldberg GR, Reina JC, Christman NT. Energy expenditure from minute-by-minute heart-rate recording: comparison with indirect calorimetry. Am J Clin Nutr 1988 Sep;48(3):552-559. [doi: 10.1093/ajcn/48.3.552] [Medline: $\underline{\text { 3414570] }}$ 
13. Green J. The heart rate method for estimating metabolic rate: review and recommendations. Comp Biochem Physiol A Mol Integr Physiol 2011 Mar;158(3):287-304. [doi: 10.1016/j.cbpa.2010.09.011] [Medline: 20869457]

14. Ferrannini E. The theoretical bases of indirect calorimetry: A review. Metabolism 1988 Mar;37(3):287-301. [doi: 10.1016/0026-0495(88)90110-2]

15. Valtueña S, Salas-Salvadó J, Lorda P. The respiratory quotient as a prognostic factor in weight-loss rebound. Int J Obes Relat Metab Disord 1997 Sep 18;21(9):811-817. [doi: 10.1038/sj.ijo.0800480] [Medline: 9376895]

16. Zurlo F, Lillioja S, Esposito-Del Puente A, Nyomba BL, Raz I, Saad MF, et al. Low ratio of fat to carbohydrate oxidation as predictor of weight gain: study of 24-h RQ. Am J Physiol 1990 Nov;259(5 Pt 1):E650-E657. [doi: 10.1152/ajpendo.1990.259.5.E650] [Medline: 2240203]

17. Gribok A, Leger JL, Stevens M, Hoyt R, Buller M, Rumpler W. Measuring the short-term substrate utilization response to high-carbohydrate and high-fat meals in the whole-body indirect calorimeter. Physiol Rep 2016 Jun 28;4(12):e12835 [FREE Full text] [doi: 10.14814/phy2.12835] [Medline: 27354539]

18. Riera CE, Dillin A. Tipping the metabolic scales towards increased longevity in mammals. Nat Cell Biol 2015 Mar 27;17(3):196-203. [doi: 10.1038/ncb3107] [Medline: 25720959]

19. Short KR, Vittone JL, Bigelow ML, Proctor DN, Nair KS. Age and aerobic exercise training effects on whole body and muscle protein metabolism. Am J Physiol Endocrinol Metab 2004 Jan;286(1):E92-101 [FREE Full text] [doi: 10.1152/ajpendo.00366.2003] [Medline: 14506079]

20. Gupta R, Ramachandran R, Venkatesan P, Anoop S, Joseph M, Thomas N. Indirect calorimetry: From bench to bedside. Indian J Endocr Metab 2017;21(4):594. [doi: 10.4103/ijem.ijem_484_16]

21. Eyth E, Basit H, Smith CJ. Glucose Tolerance Test. Treasure Island, FL: StatPearls Publishing; 2021.

\title{
Abbreviations \\ RER: respiratory exchange ratio \\ RQ: respiratory quotient \\ $\mathrm{VCO}_{2}$ : carbon dioxide production \\ $\mathbf{V O}_{2}$ : oxygen consumption
}

\author{
Edited by $G$ Eysenbach; submitted 29.10.20; peer-reviewed by J Moon; comments to author 19.11.20; revised version received \\ 07.12.20; accepted 17.04.21; published 17.05.21 \\ Please cite as: \\ Lorenz KA, Yeshurun S, Aziz R, Ortiz-Delatorre J, Bagley JR, Mor M, Kern M \\ A Handheld Metabolic Device (Lumen) to Measure Fuel Utilization in Healthy Young Adults: Device Validation Study \\ Interact J Med Res 2021;10(2):e25371 \\ URL: https://www.i-jmr.org/2021/2/e25371 \\ doi: $\underline{10.2196 / 25371}$ \\ PMID: $\underline{3870899}$
}

(CKent Arnold Lorenz, Shlomo Yeshurun, Richard Aziz, Julissa Ortiz-Delatorre, James Robert Bagley, Merav Mor, Marialice Kern. Originally published in the Interactive Journal of Medical Research (https://www.i-jmr.org/), 17.05.2021. This is an open-access article distributed under the terms of the Creative Commons Attribution License (https://creativecommons.org/licenses/by/4.0/), which permits unrestricted use, distribution, and reproduction in any medium, provided the original work, first published in the Interactive Journal of Medical Research, is properly cited. The complete bibliographic information, a link to the original publication on https://www.i-jmr.org/, as well as this copyright and license information must be included. 